\title{
Prevalence and profile of users and non- users of anabolic steroids among resistance training practitioners
}

\author{
Ericson PEREIRA', Samuel Jorge MOYSES', Sérgio Aparecido IGNÁCIO', Daniel Komarchewski MENDES', \\ Diego Sgarbi D. A. SILVA', Everdan CARNEIRO', Ana Maria Trindade Grégio HARDY², \\ Edvaldo Antônio Ribeiro ROSA ${ }^{1}$, Patrícia Vida Cassi BETTEGA ${ }^{1}$ and Aline Cristina Batista Rodrigues JOHANN ${ }^{1^{*}}$
}

\begin{abstract}
Background: To verify the prevalence and profile of users and non-users of anabolic steroid (AS) among resistance training practitioners.

Methods: An observational, cross-sectional survey was performed in 100 gyms in Curitiba city, involving 5773 individuals and self-administered questionnaires. The chi-square and z-tests of proportions were used for comparison between the groups $(p<0.05)$.

Results: $83.2 \%$ did not use, $9.1 \%$ formerly used, 3.4\% currently used, and $4.3 \%$ intended used AS. The prevalence of former or current AS users was 16.9 and $6.5 \%$ among men and women, respectively. The prevalence ratios were as follows: 1) 2.6 male users for each woman; 2) 3.3 individuals aged 30-44 years and 2.8 individuals aged 18-29years for each individual aged over 45 years. Beginners were not interested in using AS, but individuals who had trained longer had higher prevalence of AS use.

Conclusions: The gym environment encouraged the use of AS owing to aesthetic appeal. Thus, suggesting the need for actions to prevent abusive use of AS considering the practitioners profile (practitioners were young, university and single).
\end{abstract}

Keywords: Anabolic agents, Prevalence, Resistance training, Cross-sectional studies

\section{Background}

Anabolic steroids (AS) are medications containing synthetic testosterone, the male hormone. These medications may exert anabolic effects related to the growth of and increase in muscle mass, as well as androgenic effects related to male sexual characteristics [1]. Generally, AS are used for treating diseases such as hypogonadism [2] and growth deficits [3]. However, they have become a public health problem with their increased use among athletes and non-athletes for aesthetic reasons [4-6].

Inappropriate use of these medications can result in atherosclerosis, hypertension, cardiac arrhythmias, liver cancer, and prostatic hypertrophy [4, 7], as well as

\footnotetext{
* Correspondence: aline.johann@pucpr.br

'Graduate Program, Life Sciences School, Pontifical Catholic University of

Parana, Imaculada Conceição, 1155, Prado Velho, Curitiba, PR CEP 8021, Brazil

Full list of author information is available at the end of the article
}

problems such as acne, infertility, and gynecomastia [4]. Injectable AS may also cause pyomyositis [8]. In addition, behavioral problems, such as aggressiveness and mood changes, may be associated with AS use [9].

Global prevalence of AS was estimated to be a metaanalysis in 3.3\% [10]. However, this meta-analysis used studies with diverse samples, such as students, university students, resistance training practitioners, and the general public, among others.

In 2001, it was estimated that $0.3 \%$ of the adult population in Brazil used AS [11]. In 2005, this number increased to $0.9 \%$, which comprised mostly of men aged between 18 and 34 years [12]. Some studies assessed the prevalence of AS use among resistance training practitioners in gyms from various regions of the country, resulting in a prevalence range of 4.5 to $24.9 \%$ [13]. However, these studies were conducted in three to 20 gyms 
$[14,15]$, involving 117 to 510 individuals $[15,16]$, and thus may not be representative of the populations of these cities.

In the current study, we examined AS use in the population of resistance training practitioners because this population includes both current and future users of AS. Characterizing these individuals is important because information on the profile of those who have already used, is currently using, or intends to use AS can contribute to the creation and improvement of public policies aimed at preventing abusive use of AS. Thus, this study aimed to verify the prevalence and profile of users and non-users of AS among resistance training practitioners.

\section{Methods}

This study was approved by the Ethics Committee of the Pontifical Catholic University of Paraná (PUCPR), (CAAE1.524.203/2016) and was conducted according to the Consolidated Standards of Reporting Trials Statement and Helsinki Declaration of 1975 revised in 2000. All persons gave their written informed consent (Additional file 1) prior to their inclusion in the study. Details that might disclose the identity of the subjects under study were omitted.

\section{Sample}

The survey was conducted in the city of Curitiba-PR (Brazil), which has approximately 1.9 million inhabitants [17]. The number of gyms and their locations were obtained from the Regional Council of Physical Education of Paraná (CREF-PR). A total of 680 fitness centers (May/2016) were identified, including resistance training centers (gyms). Only resistance training centers were included, resulting in a total of 286 centers. The number of resistance training centers was calculated with a confidence interval of $95 \%$, and assuming that $p=\mathrm{q}=50 \%$, we calculated a total of 100 resistance training centers, with an error of $7.9 \%$. These 100 centers were used to estimate the population of resistance training practitioners in the city. Gyms were selected in a systematic randomized manner and proportional to the number of gyms in the 10 administrative regions of the city, the geographical criterion of which is determined by the Institute of Research and Urban Planning of Curitiba [18]. Personal contact was made with those responsible for the gyms to explain the purpose of the study and to obtain authorization.

In these gyms, individuals of both sexes aged above 18 years and enrolled in resistance training in different periods (morning, afternoon, and night) were identified. An average of 481 practitioners of resistance training per gym was identified. The total number of individuals was calculated with a sampling error of $1.25 \%$ and confidence interval of $95 \%$, resulting in a total of 5884 individuals. These individuals were selected in proportion to the number of practitioners of resistance training in each gym. In total, 5773 questionnaires were distributed from December 2016 to May 2017, with a sample error of $1.26 \%$.

\section{Instruments for data collection}

We prepared self-administered questionnaire (Additional file 2) containing 32 questions based on several articles in the literature $[5,19,20]$. The questions dealt with gender, age, profession, marital status, schooling, socioeconomic classification [21], practice time of resistance training, duration and objective of the training, nutritional monitoring, use of supplements, and use of AS. The questionnaire was developed and validated through the clarity, construct and content indices. Health professionals validated the aspects of construction and content, while the clarity aspect was validated with individuals of the same class, age and lifestyle of the individuals who would be researched. A pilot study was conducted that the questionnaire could be used with the intended population.

The questionnaire was constructed using the application KoboCollect (KoboCollect, Cambridge, Massachusetts, United States) in a Samsung Tablet Model Tab 2 (Samsung, Campinas, São Paulo, Brazil).

\section{Procedure of data collection}

A pre-training with researchers was conducted to standardize the approach and application of the questionnaire. The pre-training was followed by a pilot study in the PUCPR gym involving 30 individuals. These data were not included in the survey.

Data collection was performed throughout the day: 25$30 \%$ of the questionnaires were distributed in the morning, another $25-30 \%$ in the afternoon, and the remaining $40-50 \%$ in the evening until the expected number of questionnaires per gym was reached. When needed, the researchers returned to the gym at another day.

The researchers were in uniform, positioned at the entrance of the gym, and identified. The subjects were approached at the beginning or end of the workout, and given explanation of the purpose of the research. Those who accepted to participate in the study signed an informed consent form. The researchers explained the filling out of the questionnaire and clarified any possible doubts. The subjects were left alone so that they could fill the questionnaire without any influence.

\section{Data analysis}

The data were transferred from the application KoboCollect to an Excel sheet (Microsoft, Redmond, Washington, United States) and to the IBM SPSS 20.0 software (IBM SPSS, Armonk, New York, United 
States). Initially, we performed exploratory descriptive analysis of frequency distribution and percentages, with the results presented in tables. Normality of data distribution was analyzed by the Komolgorov-Smirnov test. Statistical significance was analyzed using the chi-square test and z-test, and indicated by $p<0.05$.

For a better understanding of the results, the sample was separated into four groups: the non-user (Gnu), former user (Gex), current user (Gus), and future user (Gfu) groups.

We also calculated the prevalence ratio of AS users and non-users according to gender and age. For this calculation, the generalized Poisson regression model was used $(p<0.05)$. Only for this last calculation, the Gex and Gus groups were merged, forming a new group of AS users, whereas the groups Gfu and Gnu were merged to form a new group of non-AS users.

\section{Results}

In total, 5773 individuals from 100 gyms participated in the study. Among these participants, $83.2 \%$ did not use, 9.1\% formerly used, 3.4\% currently used, and $4.3 \%$ intended to use AS. The prevalence of AS use in the Gex and Gus groups was 16.9 and 6.5\% among men and women, respectively.

The average age of the subjects was lower for men $(31.3 \pm 10.4$ years $)$ than for women $(33.2 \pm 11.3$ years $)$ $(p=0.001)$. Table 1 presents the profile of the participants. There was a higher percentage of men (57.1\%) than women (42.9\%). The Gex, Gus, and Gfu groups showed higher percentages of men than that in the Gnu group. In the Poisson model, the prevalence ratio was as follows: for each female user of AS, there was 2.6 male users of AS $(p=0.001)$.

Table 1 Profile of the study participants

\begin{tabular}{|c|c|c|c|c|c|c|}
\hline Variables & Total n (\%) & Gnu n (\%) & Gex n (\%) & Gus n (\%) & Gfu $n(\%)$ & $\mathrm{p}$ \\
\hline \multicolumn{7}{|l|}{ Sex } \\
\hline Male & 3297 (57.1\%) & $2546_{a}(53.0 \%)$ & $400_{b}(76.2 \%)$ & $159 \mathrm{~b}(82.0 \%)$ & $192_{b}(76.8 \%)$ & \multirow[t]{2}{*}{0.0001} \\
\hline Female & 2476 (42.9\%) & $2258_{a}(47.0 \%)$ & $125_{b}(23.8 \%)$ & $35_{b}(18.0 \%)$ & $58 \mathrm{~b}(23.2 \%)$ & \\
\hline \multicolumn{7}{|l|}{ Age } \\
\hline 18 to 29 years & 2836 (49.1\%) & $2291_{a}(47.7 \%)$ & $258_{\text {a.b }}(49.1 \%)$ & $109_{b}(56.2 \%)$ & $178_{c}(71.2 \%)$ & \multirow[t]{4}{*}{0.0001} \\
\hline 30 to 44 years & 2108 (36.5\%) & $1725_{a}(35.9 \%)$ & $245 \mathrm{~b}(46.7 \%)$ & $74_{a}(38.1 \%)$ & $64_{c}(25.6 \%)$ & \\
\hline 45 to 59 years & $722(12.5 \%)$ & $682_{a}(14.2 \%)$ & $22_{b}(4.2 \%)$ & $11_{b}(5.7 \%)$ & $7_{\mathrm{b}}(2.8 \%)$ & \\
\hline$\geq 60$ years & 107 (1.9\%) & $106_{a}(2.2 \%)$ & $\mathrm{O}_{\mathrm{b}}(0 \%)$ & $\mathrm{ob}_{\mathrm{b}}(0 \%)$ & $1_{a . b}(0.4 \%)$ & \\
\hline \multicolumn{7}{|l|}{ Marital Status } \\
\hline Single & 3296 (57.1\%) & $2654_{a}(55.2 \%)$ & $327 \mathrm{~b}(62.3 \%)$ & 115 a.b $(59.3 \%)$ & $200_{c}(80.0 \%)$ & \multirow[t]{4}{*}{0.0001} \\
\hline Married & 2131 (36.9\%) & $1839_{a}(38.3 \%)$ & $180_{\mathrm{a}}(34.3 \%)$ & $69 a(35.6 \%)$ & $43_{b}(17.2 \%)$ & \\
\hline Divorced & 306 (5.3\%) & $272_{a}(5.7 \%)$ & $17 \mathrm{~b}(3.2 \%)$ & $10_{a . b}(5.2 \%)$ & $7 \mathrm{a} \cdot \mathrm{b}(2.8 \%)$ & \\
\hline Widow & $40(0.7 \%)$ & $39 a(0.8 \%)$ & $1_{a}(0.2 \%)$ & $\mathrm{O}_{a}(0.0 \%)$ & $\mathrm{O}_{\mathrm{a}}(0.0 \%)$ & \\
\hline \multicolumn{7}{|l|}{ Schooling } \\
\hline $\mathrm{CHE}$ & 2865 (49.6\%) & $2416_{a}(50.3 \%)$ & $269_{a}(51.2 \%)$ & $99_{a}(51.0 \%)$ & $81_{b}(32.4 \%)$ & \multirow[t]{6}{*}{0.0001} \\
\hline IHE & 1156 (20.0\%) & $917 \mathrm{a}(19.1 \%)$ & $116_{\mathrm{a}}(22.1 \%)$ & $47_{a . b}(24.2 \%)$ & $76_{b}(30.4 \%)$ & \\
\hline $\mathrm{CHS}$ & 1270 (22.0\%) & $1066_{a}(22.2 \%)$ & $94_{b}(17.9 \%)$ & $32_{\text {a.b }}(16.5 \%)$ & $78_{c}(31.2 \%)$ & \\
\hline IHS & 212 (3.7\%) & $180_{a}(3.7 \%)$ & $16_{a}(3.0 \%)$ & $4_{a}(2.1 \%)$ & $12_{a}(4.8 \%)$ & \\
\hline CBE & 182 (3.2\%) & $153_{a}(3.2 \%)$ & $19 \mathrm{a}(3.6 \%)$ & $7 \mathrm{a}(3.6 \%)$ & $3 a(1.2 \%)$ & \\
\hline IBE & $88(1.5 \%)$ & $72_{a . b}(1.5 \%)$ & $11_{b}(2.1 \%)$ & $5_{b}(2.6 \%)$ & $\mathrm{O}_{\mathrm{a}}(0.0 \%)$ & \\
\hline \multicolumn{7}{|c|}{ Socioeconomic Class } \\
\hline Class A & $1732(30 \%)$ & 1429 a $(29.7 \%)$ & $165_{a . b}(31.4 \%)$ & $74_{b}(38.1 \%)$ & $64_{a}(25.6 \%)$ & \multirow[t]{6}{*}{0.0001} \\
\hline Class B1 & 1285 (22.3\%) & $1080_{a}(22.5 \%)$ & $112_{a . b}(21.3 \%)$ & $31_{b}(16.0 \%)$ & $62_{a}(24.8 \%)$ & \\
\hline Class B2 & $1769(30.6 \%)$ & $1472_{a . b}(30.6 \%)$ & $147_{b}(28.0 \%)$ & $62_{a . b}(32.0 \%)$ & $88_{a}(35.2 \%)$ & \\
\hline Class C1 & $750(13.0 \%)$ & $638_{a}(13.3 \%)$ & $67_{\text {a.b }}(12.8 \%)$ & $15 \mathrm{~b}(7.7 \%)$ & $30_{a . b}(12.0 \%)$ & \\
\hline Class C2 & $190(3.3 \%)$ & $159 \mathrm{a}(3.3 \%)$ & $20_{a}(3.8 \%)$ & $7 \mathrm{a}(3.6 \%)$ & $4 a(1.6 \%)$ & \\
\hline Class D-E & $47(0.8 \%)$ & $26_{a}(0.5 \%)$ & $14_{b}(2.7 \%)$ & $5_{b}(2.6 \%)$ & $2_{a . b}(0.8 \%)$ & \\
\hline
\end{tabular}


There were higher percentages of individuals aged between 18 and 29 years in the Gfu group, between 30 and 44 years in the Gex group, and between 45 and 59 years in the Gnu group. In the Poisson model, for each participant aged $45-59$ years in the Gex and Gus groups, there were 2.9 participants aged 30-44 years and 2.4 participants aged $18-29$ years $(p=0.001)$.

More than $50 \%$ of the individuals were single, with higher percentages of single participants in the Gfu and Gex groups than in the Gnu group. On the contrary, the percentage of married participants was the lowest in the Gfu group, and the percentage of divorced participants was lower in the Gex group.

Most of the participants completed upper secondary education, and the percentage of these participants was the lowest in the Gfu group. The highest percentage of individuals with incomplete upper and lower secondary education was shown in the Gfu group.

The socioeconomic classification A (upper class) and B2 (middle class) showed the highest percentages of resistance training practitioners, with higher percentage of class A in the Gus group than in the Gnu group. The percentages of class B1 (upper middle class) and C1 (lower middle class) were lower in the Gus group than in the Gnu group. The percentage of class D/E (no working) was higher in the Gex and Gus groups than in the Gnu group. This socioeconomic classification is based in 35 .
Table 2 shows percentages of AS users according to training characteristics. The percentage of participants who practiced resistance training up to 6 months and between 6 months and 1 year was higher in the Gnu group than in the other groups. However, the percentage of participants who practiced between 6 months and 1 year was already increasing in the Gfu group, equivalent to that in the Gnu group. The percentage of participants who practiced between one and 3 years was the highest in the Gfu group. The percentage of those who practiced for more than 3 years was higher in the Gex, Gus, and Gfu groups.

The percentage of those who trained two to three times a week was higher in the Gnu group than in the other groups. The same was shown by the percentage of those who trained four times a week, but the percentage in the Gfu group increased. The percentage of those who trained five or more times per week was higher in the Gex, Gus, and Gfu groups.

The Gex, Gus, and Gfu groups showed higher percentages of muscle hypertrophy, which is one of the main goals of resistance training practitioners. Moreover, the percentages of weight loss and endurance were lower in these groups than in the Gnu group. The percentage of individuals who practiced other activities besides resistance training was higher than that of individuals who did not practice other activities, and lower in the Gus and Gfu groups than in the Gex and Gus groups. The

Table 2 Percentage of use or non-use of anabolic steroids according to training characteristics

\begin{tabular}{|c|c|c|c|c|c|c|}
\hline Variables & Total n (\%) & Gnu n (\%) & Gex $n(\%)$ & Gus $n(\%)$ & Gfu $n(\%)$ & $p$ \\
\hline \multicolumn{7}{|l|}{ Duration of bodybuilding } \\
\hline$<6$ months & $1298(22.5 \%)$ & $1246_{a}(25.9 \%)$ & $21_{b}(4.0 \%)$ & $\sigma_{b}(3.1 \%)$ & $25_{c}(10.0 \%)$ & \multirow[t]{4}{*}{0.0001} \\
\hline$\geq 6$ months and $<1$ year & $821(14.2 \%)$ & $753_{a}(15.7 \%)$ & $24_{b}(4.6 \%)$ & $\sigma_{b}(3.1 \%)$ & 38 a $(15.2 \%)$ & \\
\hline$\geq 1$ year and $<3$ years & $1328(23.0)$ & $1139 a(23.7 \%)$ & $70_{b}(13.3 \%)$ & $34_{b}(17.5 \%)$ & $85_{c}(34.0 \%)$ & \\
\hline$\geq 3$ years & $2326(40.3 \%)$ & $1666_{a}(34.7 \%)$ & $410_{b}(78.1 \%)$ & $148 \mathrm{~b}(76.3 \%)$ & $102_{c}(40.8 \%)$ & \\
\hline \multicolumn{7}{|l|}{ Frequency per week } \\
\hline 2 times & $437(7.6 \%)$ & $420_{a}(8.7 \%)$ & $8 \mathrm{~b}(1.5 \%)$ & $2_{b}(1.0 \%)$ & $7 \mathrm{~b}(2.8 \%)$ & \multirow[t]{4}{*}{0.0001} \\
\hline 3 times & 1237 (21.4\%) & $1163_{a}(24.2 \%)$ & $44_{b}(8.4 \%)$ & $\sigma_{c}(3.1 \%)$ & $24_{b}(9.6 \%)$ & \\
\hline 4 times & $1526(26.4)$ & $1328_{a}(27.6 \%)$ & $121_{b}(23.0 \%)$ & $22_{c}(11.3 \%)$ & $55_{a . b}(22.0 \%)$ & \\
\hline 5 or more times & $2573(44.6 \%)$ & $1893_{a}(39.4 \%)$ & $352_{b}(67.0 \%)$ & $164_{c}(84.5 \%)$ & $164 b(65.6 \%)$ & \\
\hline \multicolumn{7}{|l|}{ Objective } \\
\hline Hypertrophy & $2953(51.2 \%)$ & $2177_{a}(45.3 \%)$ & $398_{b}(75.8 \%)$ & $172_{c}(88.7 \%)$ & $206_{c}(82.4 \%)$ & 0.0001 \\
\hline Weight loss & $2326(40.3 \%)$ & $2082_{a}(43.3 \%)$ & $132_{\text {b.c }}(25.1 \%)$ & $40_{c}(20.6 \%)$ & $72_{b}(28.8 \%)$ & 0.0001 \\
\hline Resistance & $2183(37.8 \%)$ & $1972_{a}(41.0 \%)$ & $133_{b}(25.3 \%)$ & $29_{c}(14.9 \%)$ & $49_{b . c}(19.6 \%)$ & 0.0001 \\
\hline Strength & 2001 (34.7\%) & $1673_{a}(34.8 \%)$ & $179_{a}(34.1 \%)$ & $65_{a}(33.5 \%)$ & $84_{a}(33.6 \%)$ & 0.946 \\
\hline Other & $474(8.2 \%)$ & $423_{a}(8.8 \%)$ & $41_{a}(7.8 \%)$ & $5_{b}(2.6 \%)$ & $5_{b}(2.0 \%)$ & 0.0001 \\
\hline \multicolumn{7}{|l|}{ Practicing another activity } \\
\hline Yes & 3161 (54.8\%) & 2699 a $(56.2 \%)$ & $272_{a}(51.8 \%)$ & $80_{b}(41.2 \%)$ & $110_{b}(44.0 \%)$ & \multirow[t]{2}{*}{0.0001} \\
\hline No & $2612(45.2 \%)$ & $2105_{a}(43.8 \%)$ & $253_{a}(48.2 \%)$ & $114_{b}(58.8 \%)$ & $140_{b}(56.0 \%)$ & \\
\hline
\end{tabular}


most practiced activity was running (32.4\%), followed by soccer $(22.5 \%)$, cycling (14.6\%), fights (13.5\%), and dance and swimming (5.7\%). The percentage of practitioners of fights was higher in the Gex, Gus, and Gfu groups than in the Gnu group $(p=0.0001)$. The percentages of other activities were not different between the groups.

In addition, the number of individuals in the afternoon was higher in the Gex (41.3\%), Gus (46.4\%), and Gfu $(42.8 \%)$ groups than in the Gnu group (35.4\%) $(p=0.001)$.

Table 3 presents the percentage of use of anabolic steroids according to nutritional monitoring and use of supplements. It was observed that most of the resistance training practitioners did not have nutritional monitoring and did not use supplements. The percentage of participants who had a nutritionist and used supplements was higher in the Gex, Gus, and Gfu groups.

Protein (whey protein) was the most consumed supplement among resistance training practitioners, followed by amino acids and pre-workout supplements. The percentage of individuals consuming amino acid, maltodextrin, pre-workout supplement, and other supplement was higher in the Gex, Gus, and Gfu groups than in the Gnu group, and the percentage of individuals using protein supplement was higher in the Gex and Gus groups than in the Gnu group. The other supplements used were omega 3, vitamins, creatine, thermogenics, caffeine, hypercaloric, glutamine, albumin, and post-workout supplement.

Among those who underwent nutritional monitoring, there was a higher percentage of individuals who used supplements $(42.3 \%)$ than those who did not use supplements $(19.4 \%)(p=0.0001)$.

\section{Discussion}

In this study it, can be observed that most of the participants did not use AS, whereas 9.1\% formerly used, 3.4\% currently used, and $4.3 \%$ thought intended to use AS.
Previous studies $[19,20]$ evaluating AS use among resistance training practitioners grouped individuals who had used AS together with those who were using AS, thus resulting in lower prevalence than that found in our study; if the prevalence in the Gex and Gus groups were grouped, the prevalence would be higher $(12.5 \%)$ than that in the previous study.

The sample size of gyms and participants in the literature also varied. A study in Germany carried out roughly 15 year ago evaluated 113 gyms and 621 individuals, and showed a prevalence of AS use of $13.5 \%$ [19]. In Stockholm, Sweden, the prevalence was $3.8 \%$ with 64 gyms and 1746 individuals [22]. In Al-Ain, United Arab Emirates, the prevalence was $22.1 \%$ with 18 gyms and 154 individuals [23]. However, other studies were restricted to smaller samples; for example, a study in El Paso, United States, evaluated three gyms and 516 individuals, showing a prevalence of $11.0 \%$ [24]. Moreover, a study in Boston, United States, examined five gyms and 511 individuals, showing a prevalence of $5,1 \%$ [7]. The variability of the prevalence among these studies can be attributed to not only the sample distribution, namely the numbers of gyms and individuals, but also the regional and own characteristics of the samples. For example, in the Netherlands, a study involving 92 gyms and 718 individuals obtained a prevalence of AS use of $1 \%$ [25]. However, compared with the other studies, this study had a higher percentage of women (64\%) and higher mean age ( $43.4 \pm 13.6$ years), which may explain why the number of women using AS was shown lower than that of men using AS.

The percentage of individuals who formerly used AS in the present study $(9.1 \%)$ was higher than that in a metaanalysis involving 271 articles (3.3\%) [10]. However, in this meta-analysis, the sample was heterogeneous because it included adolescents, university students, prisoners, military,

Table 3 Percentage of use of anabolic steroids according to monitoring by a nutritionist and use of supplements

\begin{tabular}{|c|c|c|c|c|c|c|}
\hline Variables & Total n (\%) & Gnu $n(\%)$ & Gex n (\%) & Gus n (\%) & Gfu $n(\%)$ & $\mathrm{p}$ \\
\hline \multicolumn{7}{|l|}{ Nutritionist } \\
\hline Yes & 1654 (28.7\%) & 1243 a $(25.9 \%)$ & $203_{b}(38.7 \%)$ & $119_{c}(61.3 \%)$ & $89 \mathrm{~b}(35.6 \%)$ & \multirow[t]{2}{*}{0.0001} \\
\hline No & 4119 (71.3\%) & $3561_{a}(74.1 \%)$ & $322_{b}(61.3 \%)$ & $75_{c}(38.7 \%)$ & $161_{b}(64.4 \%)$ & \\
\hline \multicolumn{7}{|l|}{ Supplements } \\
\hline Yes & $2334(40.4 \%)$ & $1612_{a}(33.6 \%)$ & $384_{b}(73.1 \%)$ & $174_{c}(89.7 \%)$ & $164_{d}(65.5 \%)$ & \multirow[t]{2}{*}{0.0001} \\
\hline No & 3439 (59.6\%) & $3192_{a}(66.4 \%)$ & $141_{b}(26.9 \%)$ & $20_{c}(10.3 \%)$ & $86_{d}(34.4 \%)$ & \\
\hline \multicolumn{7}{|l|}{ Type } \\
\hline Protein & $2143(91.8 \%)$ & 1455 a $(90.3 \%)$ & $364_{b}(94.8 \%)$ & $169_{b}(97.1 \%)$ & $155_{a . b}(94.5 \%)$ & 0.0001 \\
\hline Amino Acid & $807(34.6 \%)$ & $446_{a}(27.7 \%)$ & $180_{b}(46.9 \%)$ & $104_{c}(59.8 \%)$ & $77_{b}(47.0 \%)$ & 0.0001 \\
\hline Maltodextrin & $463(19.8 \%)$ & $259_{a}(16.1 \%)$ & $94_{b}(24.5 \%)$ & $68_{c}(39.1 \%)$ & $42_{b}(25.6 \%)$ & 0.0001 \\
\hline Pre-workout supplement & $801(34.3 \%)$ & $466_{a}(28.9 \%)$ & $164_{b}(42.7 \%)$ & $98_{c}(56.3 \%)$ & $73 \mathrm{~b}(44.5 \%)$ & 0.0001 \\
\hline Other & $346(14.8 \%)$ & $200_{a}(12.4 \%)$ & $69 \mathrm{~b}(18.0 \%)$ & $40_{b}(23.0 \%)$ & $37 \mathrm{~b}(22.6 \%)$ & 0.0001 \\
\hline
\end{tabular}

Z-test for proportions. a,b,c: different letters in the row indicate significant differences $(p<0.05)$. Chi square test for $p$ value 
bodybuilders, athletes, and sedentary people, among others. On the contrary, the present study examined only resistance training practitioners.

In Brazil, a systematic review presented a prevalence range of AS use of 2.1 to $31.6 \%$, with a heterogeneous sample [26]. Specifically, in resistance training practitioners, the prevalence ranged from 4.5 to $24.9 \%$. These studies showed the profile of various regions in terms of AS use, but some had relatively small sample sizes of both gyms and individuals.

The distinction between former (Gex) and current (Gus) users helped us understand the profile of AS users. Some individuals may have used AS to experiment at some point in their life and had not used it any more, whereas others may use AS recurrently. In a study conducted in Sweden, was assessed individuals who used AS at some point in their life (2.6\%), within less than 12 months $(0.9 \%)$, and within less than 30 days (0.3\%) [22]. The results showed that, as in the present study, the number of individuals who had used AS is higher than that of individuals currently using AS.

In the present study, it was possible to calculate prevalence ratio owing to the large sample size. There was a higher prevalence of AS users among men than among women, which corroborated with literature [7, 27]. Furthermore, other studies presented a prevalence close to 5.7\% [28] and 7\% [14]. However, some studies did not report the use of AS by women [15, 23, 29]. AS consumption is lower among women because they do not wish to become extremely muscular or develop male characteristics [30]. In comparison, among men, the motivation of using AS goes beyond developing the ideal body; they use AS to gain status, admiration, and popularity in their social environment [6]. In addition, AS usage allows acceptance from and identification with their peers [31].

The current study, questionnaires were distributed proportionally to the number of individuals per period. The afternoon period presented a greater percentage of former, current, and future users of AS; thus, it was concluded that the highest prevalence of AS use occurred in the afternoon. This finding was not observed in any other study. We hypothesized that the afternoon showed greater number of AS users because the gyms were emptier during this period than during other periods in the day, which minimized interference during the course of training because the devices were shared with other practitioners.

In the present study, participants aged between 18 and 29 years presented the highest percentage of future AS users. Therefore, this age group should be the target of future education and preventive actions regarding abusive AS use. Participants aged between 30 and 44 years old showed high prevalence of former AS users (11.6\%), whereas in other studies, high prevalence was shown by those aged between 18 and 29 years [14-16].

The search for improvements in quality of life, along with increasing advancement of antiaging therapies, may have prompted the increase in the use of AS. Older people have shown interests in hormone replacement; however, this treatment may cause a number of undesirable effects in young people [32]. Age-related physiological decline and societal pressure on body image are factors contributing to the increased use of AS in older men [33].

In the age group of 45-59 years, the prevalence of non-users of AS was the highest. It was verified that the frequency of AS and the number of resistance training practitioners decrease with age, showing that this activity is probably not the most sought after by this age group. Among single participants, there were high percentages of former and future users of AS. Although this high prevalence of former users of AS is supported by the literature $[16,22,34]$, no previous study evaluated individuals who intended to use AS.

Most of the participants had complete upper secondary education, as observed in other studies $[13,15]$; thus, it was suggested that people with lower level of education showed lower adherence to resistance training. There was a higher percentage of individuals with incomplete upper and lower secondary education among future users of AS, corresponding to individuals aged between 18 and 29 years, which showed the highest frequency of future users of AS. This finding emphasized the need for orientation regarding the use of AS in schools and universities, considering that AS use was also high in individuals with incomplete upper secondary education [29].

The prevalence of AS use was higher in individuals who had been practicing resistance training for a longer time. Previous studies have shown that AS use is higher in those who have been training for more than 2 years $[14,19,23]$. The frequency of sessions per week also showed similar, in accordance with the literature, which showed higher prevalence for train five times or more per week $[14,16,19]$. This higher frequency may be related to the awareness of the need for concomitant use of AS with training to obtain the desired result. Moreover, considering that these individuals train regularly, another possible motivation may be that they have not achieved the desired result solely through training.

This study found that the main objective of resistance training was muscle hypertrophy, which is consistent with the literature $[13,33]$. The percentage of individuals who formerly used, currently using, or intended to use AS was high among these practitioners because they sought higher increase in muscle mass [35].

The number of individuals who had nutritional monitoring $(28.7 \%)$ in this study was higher than that found 
by Silva et al., 2007 [20] (13.9\%). In our study, among these individuals, $42.3 \%$ used supplements, and this number is higher than the $26 \%$ observed by Pellegrini et al., 2017 [13]. The prescription of supplements is the responsibility of a nutritionist, but instead, the resistance training coaches gave the prescription [36].

The use of food supplements in Brazil has varied from 20.5 to $94.0 \%$ among practitioners of physical activities $[13,36,37]$, and our current result was within this range (40.4\%). Among AS users, these values increased to $80 \%$ [14], which is close to our current results, namely 73.1 and $89.7 \%$ in former and current users of AS, respectively. Thus, it was indicated that individuals who use AS are more likely to use supplements $[13,22]$. In our results, protein was the most common supplement used, in accordance with previous studies $[13,14,16]$, because protein supplements help to achieve muscle hypertrophy, which is one of the objectives of these practitioners [38]. Also, the addiction must be considered as a potential complication of innapropriate use of AS [39].

The limitations of the present study included possible response bias. The participants may have not provided a response representing reality because they were using AS for non-therapeutic reasons.

\section{Conclusion}

The prevalence of former and current users of AS among resistance training practitioners was 9.1 and 3.4\%, respectively, suggesting the need for actions to prevent abusive use of AS. The gym environment encouraged the use of AS owing to aesthetic appeal. However, the profile of AS users should be considered in the preventive actions.

The present study revealed that the prevalence of AS use was higher among single men in the afternoon than in other times of the day, and that the high prevalence of supplement use by users of AS. Besides resistance training, another activity that revealed a high prevalence among AS users was fighting. In addition, resistance training practitioners did not show interest in using AS at the beginning, but individuals who had been trained for longer had a higher prevalence of use. It was also observed that younger individuals between the ages of 18 and 29 with incomplete high school or higher education have a higher prevalence in relation to the use of AS. Thus, there is a need for orientation actions in schools and universities as well as the action of health professionals such as doctors, nutritionists, and physical educators to prevent abusive use of AS.

\section{Supplementary information}

Supplementary information accompanies this paper at https://doi.org/10. 1186/s12889-019-8004-6.

Additional file 1. Informed consent

Additional file 2. Questionnaire with question about use of AS.

\section{Abbreviations}

AS: Anabolic steroids; CREF-PR: Regional Council of Physical Education of Paraná; Groups: the non-user (Gnu), former user (Gex), current user (Gus), and future user (Gfu) groups; HDI: Human development index; IPPUC: Institute of Research and Urban Planning of Curitiba; PUCPR: Pontifical Catholic University of Paraná

\section{Acknowledgements}

Not applicable.

\section{Authors' contributions}

EP, SJM, EC made substantial contributions to the conception and design of the work; SAI, DKM, DSS, EARR made substantial contributions to the acquisition, analysis and interpretation of data; AMTGH, PVCB and ACBRJ had drafted the work oand substantively revised it. All authors read and approved the final manuscript.

\section{Funding}

The authors declare that they have no funding.

Availability of data and materials

All data generated or analysed during this study are included in this published article.

The datasets generated and/or analysed during the current study are not publicly available due, because the confidentiality of the participants, but are available from the corresponding author on reasonable request.

Ethics approval and consent to participate

The study was approved by the Human Research Ethics Committee of the Pontifical Catholic University of Paraná (PUCPR), with opinion number $1.524 .203 / 2016$.

Informed Consent was attached in a file, and it was written.

Consent for publication

Not applicable.

\section{Competing interests}

The authors declare that they have no competing interests.

\section{Author details}

${ }^{1}$ Graduate Program, Life Sciences School, Pontifical Catholic University of Parana, Imaculada Conceição, 1155, Prado Velho, Curitiba, PR CEP 8021, Brazil. ${ }^{2}$ Department of Physiology and Pharmacology, School of Medicine, University of Toledo, Toledo, $\mathrm{OH}$, USA.

Received: 18 June 2019 Accepted: 26 November 2019 Published online: 09 December 2019

\section{References}

1. Llewellyn W. Anabolics. Molecular Nutrition. 9th ed. Florida; 2009.

2. Ramasamy R, Wilken N, Scovell JM, Lipshultz LI. Effect of testosterone supplementation on symptoms in men with hypogonadism. Eur Urol. 2015; 67:176.

3. Giri D, Patil P, Blair J, Dharmaraj P, Ramakrishnan R, Das U, et al. Testosterone therapy improves the first year height velocity in adolescent boys with constitutional delay of growth and puberty. Int J Endocrinol Metab. 2017;15:1-4

4. Van Amsterdam J, Opperhuizen A, Hartgens F. Adverse health effects of anabolic-androgenic steroids. Regul Toxicol Pharmacol. 2010;57:117-23.

5. Petersson A, Bengtsson J, Voltaire-Carlsson A, Thiblin I. Substance abusers motives for using anabolic androgenic steroids. Drug Alcohol Depend. 2010;1:170-2.

6. Iriart JAB, Chaves JC, Orleans RG. Body cult and use of anabolic steroids by bodybuilders. Cad Saúde Pública. 2009;25:773-82 [Portuguese].

7. Kanayama G, Gruber AJ, Pope HG Jr, Borowiecki JJ, Hudson Jl. Over-thecounter drug use in gymnasiums: an underrecognized substance abuse problem? Psychother Psychosom. 2001;70:137-40.

8. Cardozo-Filho NS, Gaspar EF, Siqueira KL, Monteiro GC, Andreoli CV, Ejnisman B, et al. Pyomyositis in athletes after the use of anabolic steroids: case reports. Rev Bras Ortop. 2011;46:97-100 [Portuguese]. 
9. Lumia AR, MY MG. Impact of anabolic androgenic steroids on adolescent males. Physiol Behav. 2010;100:199-04.

10. Sagoe D, Molde H, Andreassen CS, Torsheim T, Pallesen S. The global epidemiology of anabolic-androgenic steroid use: a meta-analysis and meta-regression analysis. Ann Epidemiol. 2014;24:383-98.

11. Carlini EA, Galduróz JCF, Noto AR, Nappo SA. $1^{\circ}$ Household survey on the use of psychotropic drugs in Brazil: a study involving the country's 107 largest cities - 2001. Centro Brasileiro de Informações sobre Drogas Psicotrópicas (CEBRID), UNIFESP 2002 http://www.cebrid.epm.br/index.php. Accessed 12 Sept 2014 [Portuguese].

12. Carlini EA, Galduróz JCF. $2^{\circ}$ Household survey on the use of psychotropic drugs in Brazil: a study involving the country's 107 largest cities - 2005. Centro Brasileiro de Informações sobre Drogas Psicotrópicas (CEBRID), UNIFESP 2006 http://www.cebrid.epm.br/index.php. Accessed 12 Sept 2014 [Portuguese].

13. Pellegrini AR, Corrêa FSN, Barbosa MR. Nutritional Supplements consumption by bodybuilders of São Carlos-SP. Revista Brasileira de Nutrição Esportiva. 2017;11:59-73 [Portuguese].

14. Silva LSMF, Moreau RLM. Use of anabolic-androgenic steroids among body builders in major gym centers in São Paulo, Brazil. Rev Bras Cienc Farm. 2003:39:327-33 [Portuguese].

15. Frizon F, Macedo SMD, Yonamine M. Use of anabolic-androgenic steroids by sports practitioners attending the main gym centers in Erechim and Passo Fundo (Brazil). Rev Ciênc Farm Básica Apl. 2005;26:227-32 [Portuguese].

16. Nogueira FRS, Brito AF, Vieira TI, de Oliveira CVC, Gouveia RLB. Prevalence of use of ergogenic aids among strength training apprentices in João Pessoa Paraíba. Rev Bras Ciênc Esporte. 2015;37:56-4 [Portuguese].

17. IPARDES: Instituto Paranaense de Desenvolvimento Econômico e Social (2018) Statistical notebook - municipality of Curitiba. http://www.ipardes. gov.br. Accessed 25 Oct 2018 [Portuguese].

18. IPPUC: Instituto de Pesquisa e Planejamento Urbano de Curitiba. http:// www.ippuc.org.br/. Accessed 25 Oct 2018 [Portuguese].

19. Striegel H, Simon P, Frisch S, Roecker K, Dietz K, Dickhuth HH, et al. Anabolic ergogenic substance users in fitness-sports: a distinct group supported by the health care system. Drug Alcohol Depend. 2006:81:11-9.

20. Silva PRP, Machado Júnior LC, Figreiredo VC. Prevalence of the use of anabolic agents among strength training apprentices in Porto Alegre, RS. Arq Bras Endocrinol Metab. 2007;51:104-10 [Portuguese].

21. ABEP: Associação Brasileira de Empresas de Pesquisa (2014) Brazil's economic classification criterion. http://www.abep.org. Accessed 2 June 2015 [Portuguese].

22. Leifman H, Rehnman C, Sjöblom E, Holgersson S. Anabolic androgenic steroids use and correlates among gym users: an assessment study using questionnaires and observations at gyms in the Stockholm region. Int J Environ Res Public Health. 2011;8:2656-74.

23. Al-Falasi O, Al-Dahmani K, Al-Eisaei K, Al-Ameri K, Al-Maskari F, Nagelkerke N, et al. Knowledge, attitude and practice of anabolic steroids use among gym users in Al-Ain district, United Arab Emirates. Open Sports Med J. 2008:2:75-01.

24. Street $C$, Antonio J. Steroids from Mexico: educating the strength and conditioning community. J Strength Cond Res. 2000;14:289-4.

25. Stubbe JH, Chorus AMJ, Frank LE, de Hon O, van der Heijden PG. Prevalence of use of performance enhancing drugs by fitness Centre members. Drug Test Anal. 2014;6:434-8.

26. Abrahin OSC, De Sousa EC, Santos AM. Prevalence of the use of anabolicandrogenic steroids in Brazil: a systematic review. Subst Use Misuse. 2014;49: 1156-62.

27. Santos AF, Mendonça PMH, Santos LA, Silna NF, Tavares JKL. Anabolic steroids: concepts according to muscular activity practisers in Aracaju (SE). Psicol Estud. 2006;11:371-80 [Portuguese].

28. Sousa S, Rodrigues WRH, Silva RA, Zanuto EC. Profile of users anabolic steroids of city Presidente Prudente-SP. Revista Brasileira de Nutrição Esportiva. 2017;11:383-9 [Portuguese].

29. Silva GG, Brito AF, Nogueira FRS, Júnior F, Galan $S$, de Oliveira CVC, et al. Prevalence of anabolic-androgenic steroids on bodybuilders of Teresina -PI. RPCD. 2017;17:115-24 [Portuguese].

30. Kanayama G, Hudson JI, Pope HG Jr. Illicit anabolic-androgenic steroid use. Horm Behav. 2010;58:111-21.

31. Baptista JG, Brandão ER. Training practices at the gym: different social uses of dietary supplements and anabolic steroids. Cad Saúde Pública. 2018;34:13 [Portuguese].
32. Moraes DR, Castiel LD, APPGA R. "No" for stacked young bodybuilders, "yes" for manthers: the biomedical discourse on anabolic steroids and health. Cad Saúde Pública. 2015;31:1131-40 [Portuguese].

33. Ip EJ, Trinh K, Tenerowicz MJ, Pal J, Lindfelt TA, Perry PJ. Characteristics and behaviors of older male anabolic steroid users. J Pharm Pract. 2015;28:450-6.

34. da Silva PRP, Machado Júnior LC, Figreiredo VC, Cioffi AP, Prestes MC, Czepielewski MA. Prevalence of the use of anabolic agents among strength training apprentices in Porto Alegre, RS. Arq Bras Endocrinol Metab. 2007;51: 104 [Portuguese].

35. Maior AS, Bernasconi A, Sanches JF, Simão R, Menezes P, Miranda H, et al. Anabolic androgenic steroids use in two cities of Rio Grande do Sul. Revista Brasileira de Prescrição e Fisiologia do Exercício. 2009;3:580-1 [Portuquese].

36. Araújo LR, Andreolo J, Silva MS. Use of alimentary supplement and anabolizante for apprentices of muscular activity in the academies of Goiânia-GO. Rev Bras Ciên e Mov Brasilia. 2002;10:13-8 [Portuguese].

37. Striegel H, Simon P, Frisch S, Roecker K, Dietz K, Dickhuth HH, et al. Anabolic ergogenic substance users in fitness-sports: a distinct group supported by the health care system. Drug Alcohol Depend. 2006;81:11-9.

38. Menon D, Santos JS. Protein consumption by bodybuilding practitioners aiming muscle hypertrophy. Rev Bras Med Esporte. 2012;18:8-12 [Portuguese].

39. Quaglio GL, Fornasiero A, Mezzelani P, Moreschini S, Lugoboni F, Lechi A. Anabolic steroids: dependence and complications of chronic use. Intern Emerg Med. 2009;4:289-96.

\section{Publisher's Note}

Springer Nature remains neutral with regard to jurisdictional claims in published maps and institutional affiliations.
Ready to submit your research? Choose BMC and benefit from:

- fast, convenient online submission

- thorough peer review by experienced researchers in your field

- rapid publication on acceptance

- support for research data, including large and complex data types

- gold Open Access which fosters wider collaboration and increased citations

- maximum visibility for your research: over $100 \mathrm{M}$ website views per year

At $\mathrm{BMC}$, research is always in progress.

Learn more biomedcentral.com/submissions 